\title{
Pemanfaatan media pembelajaran dalam meningkatkan motivasi dan hasil belajar PAI di sekolah dan madrasah
}

Fitria Sartika

Program Pascasarjana Universitas Muhammadiyah Sumatera Barat, Indonesia

Email: fitriasartika22@gmail.com

Elni Desriwita

Program Pascasarjana Universitas Muhammadiyah Sumatera Barat, Indonesia

Email: elnidesriwita@gmail.com

Mahyudin Ritonga

Universitas Muhammadiyah Sumatera Barat, Indonesia

Email: mahyudinritonga@gmail.com

\begin{abstract}
Abstrak
Penelitian ini membahas tentang pemanfaatan media pembelajaran dalam meningkatkan motivasi dan hasil belajar Pendidikan Agama Islam di Sekolah dan Madrasah. Media pembelajaran merupakan hal penting yang digunakan oleh guru untuk menarik minat dan menumbuhkan motivasi siswa dalam belajar, terutama pelajaran agama Islam, agar siswa mudah memahami materi yang disampaikan tanpa merasa jenuh dan bosan mendengarkan penyampaian dari guru saja. Dengan tujuan agar materi pembelajaran PAI benar-benar bisa dipahami dan dipraktekan oleh siswa setelah dipelajari di sekolah ataupun madrasah. Metode yang digunakan dalam penelitian ini ialah pendekatan kualitatif kuantitatif yang diuraikan secara deskriptif. Temuan menyebutkan bahwa Rasulullah SAW sebagai pendidik ulung pun telah menggunakan
\end{abstract}


berbagai bentuk media dalam menyampaikan pendidikan Islam kepada para sahabat, agar para sahabat mampu memahami ajaran Islam secara baik dan benar. Hasil penelitian dari penggunaan media pembelajaran ini menunjukkan bahwa media pembelajaran mampu memberikan peningkatan terhadap motivasi belajar siswa, sangat membantu bagi pendidik untuk mencapai tujuan pembelajaran yang telah ditetapkan. Penggunaan media pembelajaran juga mampu memberikan pengaruh yang besar dalam meningkatkan hasil pembelajaran siswa dalam pembelajaran PAI di sekolah dan madrasah.

Kata Kunci: Media pembelajaran, Pendidikan Agama Islam, Peningkatan motivasi dan hasil belajar.

\begin{abstract}
This study discusses instructional media's use in increasing motivation and learning outcomes of Islamic Religious Education in Schools and Madrasas. Learning media is an important thing used by teachers to attract interest and foster student motivation in learning, mainly Islamic religious subjects. Students quickly understand the material presented without feeling bored and tired of listening to the teacher's submission. With the aim, PAI learning materials can be understood and practiced by students after studying at school and madrasa. The method used in this research is quantitative. The findings state that Rasulullāh is an excellent educator who has also used various forms of media in conveying Islamic education to friends so that friends can understand the teachings of Islam properly and correctly. The study results show that learning media can provide an increase in student motivation, greatly assisting teachers in implementing the teaching and learning process to achieve the objectives of learning material. The use of instructional media can also provide a significant influence in improving student learning outcomes in PAI learning in schools and madrasah.
\end{abstract}

Keywords: Learning media, Islamic Education, Increased motivation and learning outcome

\title{
Pendahuluan
}

Pendidikan sangat penting dalam kehidupan seseorang, pendidikan merupakan salah satu cara beribadah kepada Allah, suatu jalan untuk menjaga diri, kemuliaan dan martabat dalam hidup di dunia hingga akhirat kelak (ZTF, 
2020). Oleh karena itu, perlu adanya perbaikan dan perubahan dalam proses pendidikan, salah satunya ialah dengan menyempurnakan situasi pembelajaran yang lebih ideal. Situasi pembelajaran yang awalnya kendali belajar dipegang seutuhnya oleh guru, dirubah menjadi siswa yang memegang kendali belajar (Darling-hammond et al., 2020), sehingga siswa lebih aktif dalam berinteraksi dengan alat dan sumber belajar (Saputro, 2018), (Hoidn, 2016), dalam posisi seperti ini guru berperan sebagai fasilitator, motivator, dan evaluator.

Proses mengimplementasikan konsep "student centered" baru dalam pembelajaran ini, dibutuhkan ketertarikan atau minat yang lebih dari siswa terhadap suatu pembelajaran (Darsih, 2018). Hal ini akan muncul jika adanya suasana yang menyenangkan dalam proses kegiatan belajar mengajar. Anne Forester dan Margaret Reinhard dalam Gordon Dryden dan Jeannette Vos mengatakan bahwa variasi, kejutan, imajinasi, dan tantangan akan dapat menciptakan suasana belajar yang menyenangkan (Dryden \& Vos, 2003).

Sebagai seorang inovator guru harus mampu melakukan inovasi dalam upaya menumbuhkembangkan minat peserta didik dalam belajar seperti pemanfaatan media yang tepat. Arsyad mengatakan bahwa media dalam kegiatan pembelajaran dapat menimbulkan stimulus ingin tahu dan motivasi belajar yang baru, membangkitkan semangat dan menstimulasi siswa dalam kegiatan belajar, bahkan membawa pengaruh yang positif terhadap psikologi belajar siswa (Arsyad, 2003).

Apalagi dalam mengajarkan pelajaran agama, sangat dibutuhkan adanya media sebagai alat bantu, agar materi yang disampaikan menarik dan mudah dipahami siswa, sehingga tidak ada lagi anggapan bahwa pelajaran agama sebagai pelajaran yang membosankan bagi peserta didik. Dalam sebuah riwayat dikatakan bahwa Rasulullah SAW juga telah menggunakan media dalam mengajarkan syari'at Islam kepada para sahabat (Rofi'i, 2019), (Ramli, 2015) guna memudahkan para sahabat dalam memahami ajaran Islam yang beliau sampaikan, dan saat ini dengan perkembangan teknologi yang semakin canggih, tentu media pembelajaran akan berkembang lebih bervariasi. Sehingga perlu kiranya kita ketahui lebih luas lagi tentang media pembelajaran ini dengan segala perkembangan dan kemajuannya, sejak zaman Rasul hingga zaman modern atau era digital saat ini untuk mendukung kegiatan pembelajaran pendidikan agama Islam di sekolah atau madrasah.

Oleh karena itu, dalam artikel ini penulis akan membahas tentang apa itu media pembelajaran? Bagaimana penggunaan media ini pada masa Rasul dan juga zaman modern ini? dan bagaimana pemafaatan media ajar dalam 
pembelajaran dalam meningkatkan motivasi dan hasil belajar PAI di sekolah atau madrasah? Dengan tujuan agar guru-guru yang mengajar PAI di sekolah atau madrasah pada zaman millenial ini bisa menjadikan pembelajaran PAI sebagai pembelajaran yang menarik dan menyenangkan dengan memanfaatkan media pembelajaran.

\section{Metode}

Dalam penelitian ini digunakan metode kualitatif, hal ini didasarkan karena data yang ingin ditemukan dan dianalisis ialah berupa pernyataan, pendapat para ahli tentang media pembelajaran.

Sumber yang digunakan dalam penelitian ini adalah sumber sekunder, (Siyoto \& Sodik, 2015) yakni sumber yang berasal dari dokumen atau kepustakaan yang memuat pembahasan tentang hal-hal yang terkait dengan media pembelajaran, seperti buku, journal dan artikel-artikel ilmiah lainnya. Untuk menemukan data penelitian, terlebih dahulu dilakukan pengumpulan referensi yang terkait dengan fokus penelitian, kemudian membacanya secara cermat dan mengambil pokok pikiran yang terdapat di dalamnya, kemudian menyusunnya secara sistematis sesuai dengan pokok-pokok penelitian yang dilakukan. Adapun teknik analisis data yang digunakan ialah berupa komparasi, yakni membandingkan pendapat satu ahli dengan ahli lain, atau pendapat satu ahli dalam referensi tertentu dengan pendapatnya pada referensi lain, penggunaan analisis komparatif ini bermaksud agar peneliti lebih mudah untuk menentukan posisi dan memunculkan pendapat sendiri.

\section{Hasil dan Pembahasan}

\section{Media Pembelajaran}

Secara harfiah, media berasal dari bahasa latin medius yang artinya "perantara" atau "pengantar"(Syamsuddin, 2016). Menurut Mostefa media pembelajaran ialah semua yang dihadirkan untuk dilihat dan didengar oleh panca indera guna memahami suatu makna dengan cepat dan tepat (Mostefa, 2017).

Menurut Ernanida dan Yusra media yaitu suatu alat yang bisa dilihat dan didengar untuk menghubungkan guru dengan siswa dalam proses pembelajaran untuk meningkatkan hasil pembelajaran (Ernanida \& Yusra, 2019). Usman dan Asnawir menegaskan bahwa media pembelajaran ialah segala sesuatu 
yang bisa digunakan oleh guru dalam menyampaikan pengetahuan kepada siswa, untuk menstimulus pikiran, minat, jiwa, dan hati siswa sebaik mungkin dalam kegiatan pembelajaran (Usman \& Asnawir, 2002). Sementara Susanti dkk mengungkapkan bahwa media ialah suatu penghubung atau penyampai informasi dalam kegiatan belajar mengajar (Susanti et al., 2020).

Media adalah sarana yang dimanfaatkan oleh guru yang mengajar di kelas, seperti papan tulis, buku, dan alat-alat belajar lainnya (Abdullah, 2016). Semua sarana yang digunakan guru dalam memberikan ilmu dan pengetahuan serta mengajarkan nilai-nilai kepada siswa disebut dengan media (Layla, 2016), (Susanti et al., 2020). Secara umum media pembelajaran itu terdiri dari manusia, benda-benda, ataupun kegiatan yang mendukung terjadinya interaksi pembelajaran untuk mendapatkan ilmu pengetahuan, pengalaman, keterampilan, dan sikap bagi siswa (Sanjaya, 2008), (Ritonga et al., 2020).

Jadi, media pembelajaran berarti segala sesuatu yang digunakan oleh guru ketika melaksanakan kegiatan pembelajaran, berupa perangkat dan bahan yang memfasilitasi, memudahkan, dan meningkatkan proses pembelajaran di dalam kelas untuk menyampaikan ilmu, pengetahuan, serta makna dan nilainilai kepada siswa. Dengan menggunakan media pembelajaran dalam mengajar, sangat membantu dan mempercepat proses pembelajaran, karena siswa akan lebih aktif berinteraksi dengan media pembelajaran, dan penggunaan media juga dapat mengaktifkan lebih dari satu indera siswa.

Penggunaan Media pembelajaran dalam proses belajar mengajar sangat dibutuhkan oleh seorang guru untuk menyampaikan pengetahuan kepada peserta didik (Sudrajat, Prasojo, Zulkarnain, 2018). Secara umum, penggunaan media pembelajaran akan membuat proses belajar mengajar lebih bervariasi, dan berjalan lebih efektif dan efisien. Untuk lebih rinci, maka diuraikan sebagai berikut (Bahruddin, 2011):

Pertama, Memperkaya pembelajaran, penelitian telah menunjukkan bahwa media memiliki peran penting dalam memperkaya pembelajaran, memperluas pengalaman siswa, memfasilitasi pembangunan konsep dan mengatasi segala keterbatasan dengan menggunakan berbagai sarana komunikasi yang menawarkan media pembelajaran yang menarik.

Kedua, Mencapai ekonomi pendidikan, yang dimaksudkan untuk membuat proses pendidikan lebih ekonomis dengan meningkatkan pembelajaran. Tujuan utama dari pendidikan adalah untuk mencapai tujuan belajar yang terukur pada tingkat yang efektif dan efisien. 
Ketiga, Untuk membantu merangsang minat dan perhatian siswa dalam belajar, siswa akan memperoleh pengalaman yang menarik melalui penggunaan media pendidikan yang bervariasi dalam mencapai tujuan pembelajaran. Semakin banyak pengalaman siswa dalam belajar, semakin menjadikan siswa tertarik untuk menuntaskan rasa keingintahuan.

Keempat, Membantu meningkatkan pengalaman siswa, membuat siswa lebih siap untuk belajar dengan menggunakan berbagai metode pengajaran, siswa memperoleh pengalaman baru yang membuatnya lebih bersedia untuk melanjutkan pembelajaran.

Kelima, Untuk menarik partisipasi dari semua indera siswa dalam proses pembelajaran, partisipasi semua indera dalam proses pendidikan mengarah pada konsolidasi dan pendalaman pembelajaran, dalam hal ini pendidikan membantu melibatkan semua indrea siswa.

Keenam, Untuk membantu meningkatkan partisipasi positif siswa dalam akuisisi pengalaman, di mana sarana pendidikan mengembangkan kemampuan siswa untuk mengamati dengan pengamatan yang akurat serta berpikir ilmiah untuk mencapai solusi masalah. Metode ini tentu meningkatkan kualitas pembelajaran dan meningkatkan kinerja murid.

Dari berbagai literature ditemukan bahwa penggunaan media pembelajaran memberikan manfaat yang sangat besar, pertama, Memperjelas makna bahan pembelajaran, sehingga materi atau pesan lebih cepat diterima dan dipahami peserta didik (Faizi et al., 2013). Kedua, menjadikan guru lebih terampil dalam menggunakan metode pemelajaran yang lebih variatif (Sudarsana et al., 2019), (Sari \& Wilujeng, 2020). Ketiga, peserta didik akan jauh lebih aktif dalam kegiatan pembelajaran, seperti mengamati, melaksanakan atau menirukan, serta mendemonstrasikan materi pembelajaran.

Keempat, peserta didik akan lebih meningkat motivasinya (Susanti et al., 2020). Kelima, materi yang disampaikan akan lebih jelas dipahami peserta didik, keenam, problematika pembelajaran yang dari berbagai aspek akan dapat di atasi.

Media pembelajaran tidak hanya dimaksudkan sebagai alat yang dapat membantu guru, melainkan juga sebagai alat untuk menolong peserta didik dalam memahami materi yang disampaikan oleh guru. Lebih luas dari itu juga, media pembelajaran yang tersedia pada saat ini dapat menjadi sebagai sumber dan metode pembelajaran. 


\section{Media Pembelajaran yang digunakan dalam Pembelajaran PAI di Sekolah dan Madrasah}

Menurut pendapat orang Arab, media pembelajaran pertama bagi anak itu ialah keluarga dan sanak famili atau karib kerabat mereka, dari sana seorang peserta didik mulai meniru apa yang mereka lihat di hadapan mereka, apa yang mereka dengar, yang mereka perhatikan dalam keluarga, suku (Al-Abrasyi, 1988), dan orang terdekat yang mereka jumpai.

Dalam pendidikan Islam, media pembelajaran sudah digunakan sejak zaman Rasulullah SAW. Rasulullah SAW sebagai pendidik ulung telah menggunakan berbagai bentuk media dalam menyampaikan ajaran Islam kepada para sahabat pada masa kerasulan, walaupun dengan media ajar seadanya, tapi Nabi mampu membuat sahabat memahami apa yang beliau sampaikan dengan cepat dan tepat. Dalam hadits disebutkan bahwa Nabi pernah menggunakan gambar dalam berdakwah, menggunakan jemari tangan beliau, dn juga menggunakan kerikil.

Pada zaman modern ini, perkembangan dunia sudah semakin canggih, begitupun dengan media yang bisa digunakan dalam menyampaikan materi pembelajaran. Secara garis besar, media pembelajaran zaman modern terbagi tiga bagian, yaitu media yang bisa dilihat disebut visual, media yang bisa didengar disebut audio, media yang bisa dilihat dan didengar disebut dengan audio visual.

Ketiga media di atas bisa digunakan dalam menyampaikan materi ajar PAI di sekolah ataupun madrasah, baik visual, audio, dan audio visual bisa dimanfaatkan ketika melaksanakan kegiatan pembelajaran, hanya saja perlu disesuaikan dengan materi yang diajarkan. Menurut analisa peneliti berdasarkan lima materi yang harus diajarkan dalam PAI dengan berbagai media sebagai berikut: pertama, Media Visual dapat dimafaatkan dalam menyampaikan pelajaran yang berkaitan dengan ibadah, seperti materi dalam fiqih yaitu shalat dengan memperlihatkan gambar-gambar posisi shalat yang benar, dalam Qur'an Hadits misalnya menyambung ayat dengan menggunakan kertas karton warna warni yang dituliskan ayat-ayat/hadits di sana, kemudian cocokkan dengan terjemahannya, dan lain sebagainya.

Kedua, Media Audio, media audio ini salah satu penggunaannya pada materi membaca ayat atau hadits, diperdengarkan melalui rekaman atau kaset dan sejenisnya, agar bacaannya sesuai dengan tajwid dan penggalan-penggalan bacaan jadi lebih tepat, atau dalam belajar qira'ah dan muhadatsah bahasa 
Arab.

Ketiga, Media Audio Visual, media audio visual bisa digunakan dalam berbagai materi, misalnya belajar mufradat bahasa arab agar lebih menarik bagi anak-anak, kemudian belajar SKI melalui film-film animasi tentang suatu materi yang diajarkan, dalam belajar akidah akhlak guru bisa menayangkan film-film yang bermuatan akhlak mulia, menyampaikan materi ilmu tajwid tentang makhraj huruf misalnya, dan lains sebagainya.

\section{Pemanfaatan Media Pembelajaran dalam Meningkatkan Motivasi dan Hasil Belajar PAI}

Hasil penelitian yang penulis lakukan pada tahun 2015 diketahui melalui pengamatan pembelajaran PAI di SMP Islam Raudhatul Jannah Payakumbuh. Pembelajaran PAI di sana memakai PAI Terpadu. Dalam PAI Terpadu tersebut menggabungkan lima mata pelajaran, ada fiqih, akidah akhlak, Qur'an hadits, SKI, dan bahasa Arab.

Berdasarkan pengamatan penulis, untuk tingkatSMP, media pembelajaran sangat efektif digunakan dalam proses belajar mengajar. Usia siswa yang sedang menginjak fase remaja yang cenderung kritis dan suka menarik perhatian guru. Sikap yang ditunjukkan siswa dalam belajar harus menjadi perhatian khusus bagi guru, dan guru harus bisa mencari solusi terbaik, agar siswa tersebut mampu menerima materi pembelajaran dengan baik.

Dalam kegiatan belajar mengajar seringkali ditemukan siswa yang pintar, tapi kerap berulah ketika belajar, seperti jalan-jalan, mengganggu teman, dan sebagainya. Walalupun sebenarnya siswa tersebut mampu menyerap materi dengan baik, tapi teman yang cara belajarnya focus akan terganggu, dan hasilnya tujuan pembelajaran tidak tercapai secara menyeluruh. Sehingga, penggunaan media pembelajaran sangat tepat untuk meminimalisir berbagai problema yang harus dihadapi guru dalam mengajar, untuk mencapai tujuan pembelajaran yang diharapkan.

Dalam menyampaikan materi bahasa Arab, penulis mencoba menggunakan media audio visual dengan menggunakan infocus. Bahan ajar disuguhkan dalam bentuk power point semenarik mungkin untuk siswa usia remaja, sedikit warna-warni dan gambar yang diberi backsound. Di samping itu, penulis juga menjelaskan materi tersebut dengan suara sendiri untuk memaksimalkan pengucapan huruf, agar sesuai dengan makhrajnya dan 
intonasi yang jelas.

Hasilnya, siswa tenang dan diam melihat ke layar di depan, dan mengikuti atau mengulang pengucapan mufradat-mufradat atau bacaan yang ditampilkan. Menghafal mufradat dan materi bahasa Arab pun menjadi lebih mudah. Sehingga terdapat peningkatan dan pengaruh yang positif terhadap hasil pembelajaran bahasa Arab siswa.

Dalam mempelajari materi fiqih di kelas IX, guru PAI SMP Islam Raudhatul Jannah memiliki metode khusus, yaitu metode visitasi dan diskusi, dominan menggunakan media visual. Guru hanya menjelaskan point-point penting dalam materi pembelajaran sambil diskusi terbuka. Selain itu, peserta didik disuguhkan tugas mengamati objek yang sesuai dengan materi pembelajaran dengan realita di lapangan atau di lingkungan tempat tinggal masing-masing siswa.

Hasil pengamatan lapangan tersebut harus dikumpulkan dalam bentuk tulisan artikel yang ditulis rapi menggunakan computer atau laptop dan diprint. Setelah kembali ke sekolah, paper tersebut dibahas dalam bentuk diskusi terstruktur, sehingga siswa mudah memahami materi secara teori dan juga paham prakteknya. Karena memang tujuan dari pembelajaran fiqih ialah siswa mampu mengimplementasikan atau mempraktekkan materi tersebut menjadi amal ibadah dalam kehidupan sehari-hari.

Misalnya, materi tentang penyembelihan hewan qurban, materi ini sengaja di bahas pada bulan haji, agar siswa bisa terjun langsung ke lapangan. Siswa harus melihat langsung cara penyembelihan hewan qurban, mewawancarai orang yang menyembelih dan juga orang yang berqurban, kemudian menguraikannya dalam tulisan, sehingga siswa tidak hanya paham teori tapi juga praktek berqurbanyang sebenarnya mereka pahami dengan baik.

Pada tahun 2016 penulis juga melakukan penelitian terhadap siswa Madrasah Ibtidaiyah, yaitu MIN Parambahan Kota Payakumbuh. Media yang diteliti pada saat itu ialah terkait dengan penggunaan media audio visual. Audio visual sebagai media tidak hanya mengandalkan satu indera siswa saja, akan tetapi dapat diterima oleh indera pendengaran sekaligus penglihatan. Dengan kelebihan ini penulis berharap media ini bisa meningkatkan minat dan belajar sekaligus meningkatkan kemampuan penyerapan materi oleh peserta didik. Sehingga hasil pembelajaran menjadi lebih baik dan tujuan pembelajaran tercapai sesuai harapan.

Siswa usia SD/MI sangat menyukai hal yang berbentuk gambar, warna- 
warni, suara-suara yang menarik seperti nyanyian, atau suara khas anak-anak. Maka penulis memilih video dan film animasi yang diperagakan dengan suara khas anak-anak untuk digunakan dalam menyampaikan materi pembelajaran pada kelas eksperimen.

Peneliti telah melakukan penelitian terhadap siswa di MI Parambahan. Materi penelitian ialah bahasa Arab bagian maharah istima' dan mufradat. Karena pembelajaran bahasa Arab, dasarnya ialah penghafalan mufradat. Apabila siswa hafal mufradat untuk satu Bab tersebut, maka materi dalam maharah kalam, qira'ah, dan kitabah akan mudah diserap oleh siswa.

Pada tahap observasi awal, penulis meminta dokumentasi hasil ulangan harian siswa kepada guru bahasa Arab yang mengajar di kelas IV MIN Parambahan tersebut. Hasil ulangan siswa tersebut rata-rata masih rendah, hanya ada beberapa orang yang di atas KKM. Dari rekap nilai ulangan tersebut dapat diketahui bahwa nilai siswa lokal IV A lebih baik dari nilai siswa lokal IV B. Sehingga penulis memilih kelas IV A sebagai kelas kontrol, dan kelas IV B sebagai kelas eksperimen.

Kelas eksperimen diberlakukan pembelajaran menggunakan media audio visual setiap pertemuan selama penelitian, sedangkan kelas kontrol tanpa menggunakan media apapun, hanya menggunakan buku bahan ajar yang biasa digunakan oleh guru bahasa Arab seperti biasa. Setelah jadwal untuk pelaksanaan ulangan harian, siswa kelas eksperimen dan kelas kontrol diberikan soal ulangan yang sama. Hasil ulangan tersebut menunjukkan peningkatan yang signifikan pada kelas eksperimen atau lokal IV B.

Semua data penelitian dikumpulkan, baik hasil observasi, dokumentasi dan hasil post test atau nilai ulangan harian. Hasil penelitian tersebut dianalisis menggunakan analisis statistik uji $t$ menggunakan microsoft excel dan penghitungan manual.

Nilai pre test siswa kelas eksperimen paling tinggi 100, dan paling rendah 10, dengan rata-rata 60. Dari hasil eksperimen diketahui bahwa pembelajaran dengan media audio visual nilai ulangan harian siswa paling tinggi 100, dan paling rendah 85 , dengan rata-rata 95,59. Nilai pre test siswa kelas kontrol paling tinggi 100 , paling rendah 10 , dengan rata-rata 71,18 . Setelah penelitian tanpa menggunakan media atau post test, nilai paling tinggi 100, paling rendah 15 , dengan rata-rata 71,47 .

Kemudian dilakukan uji normalitas terhadap data tersebut, uji normalitas ini menggunakan rumus liliefors. Menurut (Syafril, 2000) uji liliefors yaitu apabila 
$\mathrm{L}_{0}<\mathrm{L}_{\mathrm{t}}$ maka data tersebut normal, tapi apabila $\mathrm{L}_{0}>\mathrm{L}_{\mathrm{t}}$ maka data dinyatakan tidak normal. Hasil uji normalitas kelas kontrol menunjukkan bahwa $\mathrm{L}_{0}>\mathrm{L}_{\mathrm{t}}$ yaitu $\mathrm{L}_{0}=0,219$ dan $\mathrm{L}_{\mathrm{t}}=0,206$. Karena $\mathrm{L}_{0}>\mathrm{L}_{\mathrm{t}}$ maka $\mathrm{H}_{0}$ ditolak dan $\mathrm{H}_{1}$ diterima, berarti data tidak berdistribusi normal. Hasil uji normalitas kelas eksperimen menunjukkan bahwa $\mathrm{L}_{0}<\mathrm{L}_{\mathrm{t}}$ yaitu $\mathrm{L}_{0}=0,201$ dan $\mathrm{L}_{\mathrm{t}}=0,206$. Karena $\mathrm{L}_{0}<\mathrm{L}_{\mathrm{t}}$ maka $\mathrm{H}_{0}$ diterima berarti data berdistribusi normal.

Setelah uji normalitas data, dilakukan uji homogenitas data dengan menggunakan metode barlet, yaitu apabila $\mathrm{f}_{0}<\mathrm{f}_{\mathrm{t}}$ maka variasi data homogen, sedangkan jika $f_{0}>f_{t}$ maka data tidak mempunyai variasi yang homogen. Hasilnya menunjukkan bahwa $f$ hitung atau $f_{0}$ lebih besar dari $f$ tabel atau $f_{t}$ yaitu $f_{0=} 28,90$ dan $f_{t=2} 2,35$, maka $H_{0}$ ditolak dan $H_{1}$ diterima, berarti data mempunyai variasi yang tidak homogen.

Setelah uji normalitas dan uji homogenitas maka dilakukan uji hipotesis data, yaitu mencari thitung atau $t_{0}$ dan $t$ tabel atau $t_{t}$. Hasilnya menunjukkan bahwa $t_{0}$ lebih besar dari $t_{t}$, yaitu $t_{0}=3,45$ dan $t_{t}=1,696$. Maka $H_{0}$ ditolak dan $\mathrm{H}_{1}$ diterima, berarti hasil pembelajaran menggunakan media audio visual lebih baik daripada hasil pembelajaran tanpa menggunakan media.

Berdasarkan analisis data tersebut dapat diambil kesimpulan bahwa media audio visual dapat memberikan pengaruh yang positif dalam meningkatkan hasil pembelajaran bahasa Arab pada siswa kelas IV MIN Parambahan Kota Payakumbuh. Sehingga media ini layak dan recomended untuk digunakan oleh guru PAI dalam materi mufradat bahasa Arab tingkat MI.

Di antara keuntungan yang penulis rasakan saat melakukan proses pembelajaran dengan menggunakan media audio visual adalah: Pertama, Timbulnya semangat mengajar melihat antusias peserta didik mengikuti pembelajaran. Sehingga dapat dirasakan bahwa semangat peserta didik sebanding lurus dengan semangat pendidik.

Kedua, guru bisa lebih ekspresif dalam mengajar, karena tidak terikat tempat harus selalu berada di depan atau di dekat papan tulis. Cukup dengan menyaksikan video yang ditayangkan di depan kelas. Ketiga, meransang naluri berkreasi seorang guru. Sehingga kemasanmateri pembelajaran lebih menarik untuk disuguhkan kepada siswa. Keempat, Siswa lebih focus dalam belajar dan tertarik mengikuti pembelajaran hingga selesai, dan meminta penulis untuk mengajarkan mereka menggunakan media ini secara berlanjut.

Di sisi lain, penulis juga mengalami beberapa kendala dalam pelaksanaan pembelajaran menggunakan media audio visual ini, seperti: 
Pertama, persiapan bahan ajar yang cukup menyita waktu. Tidak seperti pembelajaran konvensional yang mana bahan ajarnya sudah selesai dalam bentuk buku paket, pada pembelajaran dengan menggunakan media ini, penulis harus mencari video yang tepat dan sesuai dengan materi yang akan diajarkan. Video dan film animasi yang tersedia dalam internet tidak semuanya benar pelafalan makhraj hurufnya, sehingga penulis harus benar-benar teliti dalam memilih film animasi dan video yang ada, dan harus menyiapkan materi tambahan atau penguat dari yang telah ada di video dengan power point untuk ditayangkan semenarik mungkin.

Kedua, kondisi lokal yang masih sederhana, mengharuskan penulis memanage sendiri agar penggunaan infokus bisa maksimal dan tayangan pada layar bisa dilihat dengan baik oleh siswa dari belakang. Speaker sekolah tidak bisa untuk digunakan dalam kelas, sehingga penulis harus membawa speaker kecil dari rumah untuk memaksimalkan suara video atau fil animasi yang ditayangkan selama proses pembelajaran.

Ketiga, gangguan listrik. Karena media yang penulis gunakan sangat bergantung pada aliran listrik, maka gangguan listrik seperti terputusnya aliran listrik, juga sangat mengganggu jalannya proses pembelajaran.

\section{Kesimpulan}

Media audio visual dapat mengaktifkan indera penglihatan dan indera pendengaran siswa secara bersamaan. Namun, beberapa materi lebih tepat menggunakan media visual ataupun audio, karena tidak semua materi PAI bisa disampaikan melalui audio visual. Guru bisa memanfaatkan berbagai media ajar yang berkembang di era modern ini. Dukungan teknologi informasi, memungkinkan guru dapat mengakses media yang dibutuhkan dan dikreasikan agar lebih menarik dan sesuai dengan materi yang akan disampaikan.

\section{Daftar Pustaka}

Abdullah, R. (2016). al-Wasa'il al-Ta'limiyyah fi Ta'lim al-Lughah al-'Arabiyyah Linnathiqina bi Ghoiriha [Teaching Media in the Teaching of Arabic Language to Non-Native Arabic Speakers]. Dinamika Ilmu, 16(1), 93-106. Al-Abrasyi, M. 'Athiyyah. (1988). al-Tarbiyyah al-Islamiyyah wa Falasifatuha. Dar al-Fikr al'-Araby.

Arsyad, A. (2003). Media Pembelajaran. Raja Grafindo Persada. 
Bahruddin, U. (2011). Maharat At-Tadris. UIN Maliki Press.

Darling-hammond, L., Flook, L., Cook-harvey, C., Barron, B., \& Osher, D. (2020). Implications for educational practice of the science of learning and development. Applied Developmental Science, 24(2), 97-140. https:// doi.org/10.1080/10888691.2018.1537791

Darsih, E. (2018). Learner-Centered Teaching: What Makes It Effective. Indonesian EFL Journal, 4(1), 33-42. https://doi.org/10.25134/ieflj. v4i1.796

Dryden, G., \& Vos, J. (2003). Revolusi cara belajar (the learning revolution): belajar akan lebih efektif kalau Anda dalam keadaan "fun" bagian II: sekolah masa depan (Issue 2). Kaifa.

Ernanida, \& Yusra, R. Al. (2019). Media Audio Visual Dalam Pembelajaran PAI. Al Murabbi: Jurnal Pendidikan Islam, 2(1), 101-112. https://doi. org/10.35891/amb.v5i1.1854

Faizi, R., El Afia, A., \& Chiheb, R. (2013). Exploring the Potential Benefits of Using Social Media in Education. International Journal of Engineering Pedagogy (IJEP), 3(4), 50-53. https://doi.org/10.3991/ijep.v3i4.2836

Hoidn, S. (2016). The Pedagogical Concept of Student-Centred Learning in the Context of European Higher Education Reforms. European Scientific Journal, ESJ, 12(28), 439-458. https://doi.org/10.19044/esj.2016. v12n28p439

Layla, S. (2016). Dawr al-Wasa'il fi al-Amaliyyah al-Ta'limiyyah. Al-Atsar, 26(September), 145-154. https://doi.org/10.35156/1174-000-026-014

Mostefa, N. (2017). al-Wasa'il al-Ta'limiyyah al-Haditsah wa Ahamiyatuha fi Tadris al-Lughah al-'Arabiyyah fi al-Thur al-Tsanawy. Jasur Al-Ma'rifah, 10, 547-562.

Ritonga, M., Nazir, A., \& Wahyuni, S. (2020). Pengembangan Model Pembelajaran Bahasa Arab Berbasis Teknologi Informasi $\mathcal{E}$ Komunikasi dalam Dialektika Revolusi Industri 4.0. Deepublish. https://books.google.co.id/ books?hl=id\& $1 \mathrm{r}=\& \mathrm{id}=$ OEXYDwAAQBAJ\&oi=fnd\&pg=PP1\&ots=sbr9Fjm__t\&sig=gqKsqW7fcokp_ya5MQd1zMZfQGE\&redir_es$\mathrm{c}=\mathrm{y} \# \mathrm{v}=$ onepage $\& \mathrm{q} \& \mathrm{f}=$ false

Rofi'i, A. (2019). Metode Rasulullah dalam Pendidikan Karakter Perspektif Al-Qur'an. KORDINAT, XVIII(1), 49-74. https://doi.org/10.1017/ CBO9781107415324.004 
Sanjaya, W. (2008). Strategi Pembelajaran Berorientasi Standar Proses Pendidikan (Issue 2). Prenada Media.

Saputro, S. D. (2018). The Application of Student Centered Learning Through Lesson Study on Quality and Learning Results. ISLLAC: Journal of Intensive Studies on Language, Literature, Art, and Culture, 2(2), 84-91. https://doi. org/10.17977/um006v2i22018p084

Sari, W. K., \& Wilujeng, I. (2020). Education Change in the Industry 4.0: Candidate Science Teacher Perspective. Journal of Physics: Conference Series, 1440(1), 0-7. https://doi.org/10.1088/1742-6596/1440/1/012090

Sudarsana, I. K., Nakayanti, A. R., Sapta, A., Haimah, Satria, E., Saddhono, K., Achmad Daengs, G. S., Putut, E., Helda, T., \& Mursalin, M. (2019). Technology Application in Education and Learning Process. Journal of Physics: Conference Series, 1363(1-6). https://doi.org/10.1088/17426596/1363/1/012061.

Sudrajat, A., Prasojo, L.D., Zulkarnain, Z (2018). "Be a scientist" learning media using adobe flash CS3 program containing the materials of the influence of islamic religion and culture in Indonesia for Grade X of vocational school. Journal of Social Studies (JSS), 14(1). 90-100. https://doi. org/10.21831/jss.v14i1.21656

Susanti, E., Ritonga, M., \& Bambang, B. (2020). Pengaruh Penggunaan Media Powerpoint Terhadap Minat Belajar Bahasa Arab Siswa. Arabiyatuna: Jurnal Bahasa Arab, 4(1), 179-191. https://doi.org/10.29240/jba. v4i1.1406

Syamsuddin, F. H. (2016). al-Wasa'il al-Ta'limiyyah al-Mashurah: al-Mafahim, alWasa'il al-Malmusah, Ba'd Asykal al-Wasa'il, Wasa'il al-Ta'lim al-Eliktruny. Syams Linnasyr wa al-I'lam. www.shams-group.net

Usman, M. B., \& Asnawir. (2002). Media Pembelajaran. Ciputat Press.

ZTF, P. B. (2020). From the centre to periphery: The Middle Eastern impacts on Islamic education in Indonesia. Journal of Social Studies (JSS), 16(1), 65-82. https://doi.org/10.21831/jss.v16i1.34702 